symptom in this condition, and vomiting is seldom described.

In the case presented, the impacted foreign body did not cause biliopancreatic flow obstruction, despite the tiny dimensions of the papilla. The only effect was increasing vomiting, probably on a reflex basis. Endoscopy is necessary to show this lesion.

1 Walker WA, Durie PR, Hamilton JR, Walker-Smith JA, Watkins JB. Pediatric gastrointestinal disease, Vol. 1. St Louis: Mosby, 1996:198-9.

2 Sferco A, Cantor D, Casal M, Machado E. Foreign body
Odditis. Acta Gastroenterol Latinoam 1970;2:25-7.

3 Rao BK, Lieberman LM. Intermittent common bile duct obstruction at ampulla of Vater due to chicken bone impaction: diagnosis by hepatobiliary imaging. Clin Nucl Med 1981;6:59-61.

4 Zonnebelt S. Wolberg W. Ascending cholangitis secondary to chicken bone lodged at the ampulla of Vater. Am F Surg 1981;141:610-11.

5 Danzi JT. Two cases of acute pancreatitis due to foreign body. Gastrointest Endosc 1986;32:360-1.

6 Meltzer SJ, Goldberg MD. Recurrent pancreatitis caused by vegetable matter obstruction. Am F Gastroenterol 1986;818: 1091-2.

7 Sakai T, Kihara M, Wagayama H, Shimizu A, Kunlyoshi M, Tameda Y. A case of recurrent choledocholithiasis due to foreign bodies (fish bones) after endoscopic sphincterotomy. Nippon Shokakibyo Gakkai Zasshi 1997;94:143-7.

\title{
STAMPS IN PAEDIATRICS
}

\section{UNICEF}

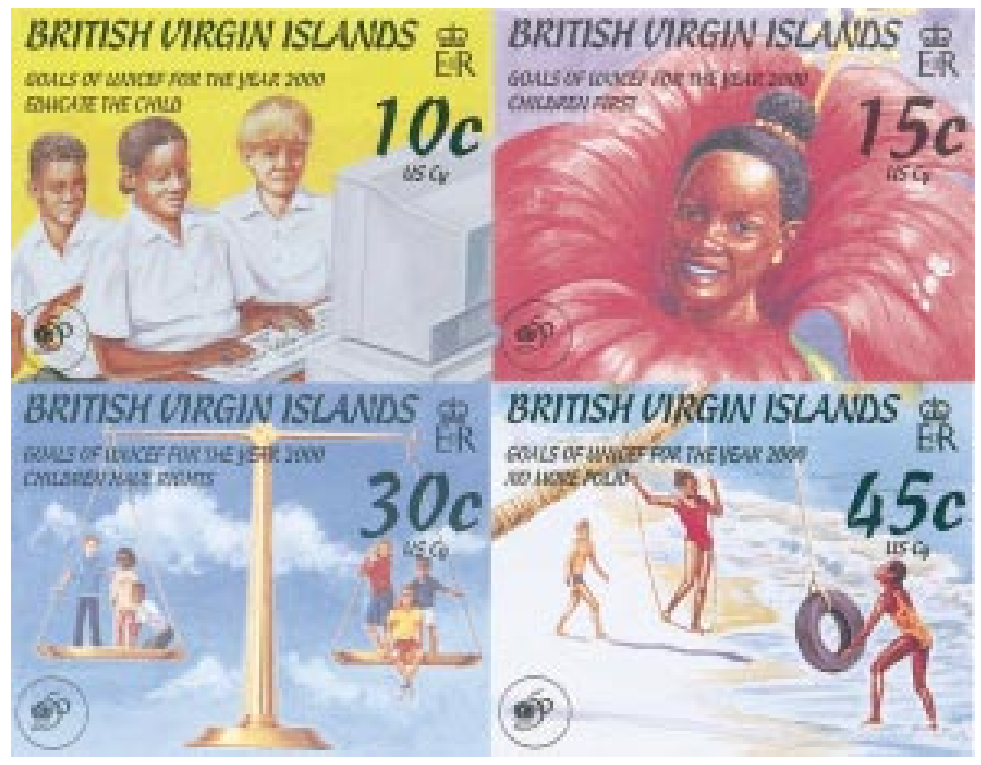

The goals of UNICEF for the year 2000 are illustrated on the set of four stamps from the British Virgin Islands issued in 1996 to mark the 50th anniversary of the organisation. The themes depicted are "Educate the child", "Children first", "Children have rights", and "No more polio". The UNICEF logo incorporating the number 50 is on each of the stamps.

M K DAVIES A J MAYNE 